\title{
openheart ECG characteristics according to the presence of late gadolinium enhancement on cardiac MRI in hypertrophic cardiomyopathy
}

\author{
Sylvain Grall, ${ }^{1,2}$ Loïc Biere, ${ }^{1,2}$ Guillaume Clerfond, ${ }^{1,2}$ Victor Mateus, ${ }^{1,2}$ \\ Fabrice Prunier, ${ }^{1,2}$ Alain Furber ${ }^{1,2}$
}

To cite: Grall S, Biere L, Clerfond G, et al. ECG characteristics according to the presence of late gadolinium enhancement on cardiac MRI in hypertrophic cardiomyopathy. Open Heart 2014:1:e000101.

doi:10.1136/openhrt-2014000101

Received 27 February 2014 Revised 29 May 2014 Accepted 15 July 2014
CrossMark

\footnotetext{
${ }^{1}$ Université d'Angers, Laboratoire

"Cardioprotection, Remodelage et Thrombose", Angers, France

${ }^{2}$ Centre Hospitalier Universitaire d'Angers, Service de Cardiologie, Angers, France
}

Correspondence to Dr Sylvain Grall; sygrall@chu-angers.fr

\section{ABSTRACT}

Background: Late gadolinium enhancement (LGE) on cardiac MRI (CMR) has been described as an independent predictive factor of cardiovascular events among patients with hypertrophic cardiomyopathy (HCM). LGE and $Q$ waves are considered as myocardial scar markers but their relation in the context of $\mathrm{HCM}$ is poorly established and has to be more supported. The objective of the study was to compare ECG findings in the presence or absence of LGE.

Methods: 42 patients with HCM confirmed by CMR were included in the study. ECG abnormalities including abnormal $Q$ waves and five ECG scores of left ventricular hypertrophy were assessed and compared according to LGE presence and its extension. Some CMR features, such as septal to posterior wall thickness ratio, were also studied according to the presence of LGE and the presence of abnormal $Q$ waves.

Results: Abnormal $Q$ waves were more prevalent in the LGE (+) group (60\% vs $12 \% ; p=0.002)$, but there was no correlation between location of $Q$ waves on ECG and territory of LGE on CMR. Among patients with LGE, quantitative analysis of LGE was not different in the presence or absence of $Q$ waves. In contrast to the LGE mass, septal to posterior wall thickness was higher in patients with abnormal $Q$ waves $(2.3 \pm 0.7$ vs $1.6 \pm 0.5 ; p=0.012$ ).

Conclusions: Although abnormal $Q$ waves were more prevalent in the presence of LGE, no correlation was found with the LGE location and extent. These data suggest that abnormal electrical activation of the hypertrophied ventricular septum represented by a high septal to posterior wall thickness ratio seems to be an important mechanism of abnormal $Q$ waves in HCM.

\section{INTRODUCTION}

Hypertrophic cardiomyopathy (HCM) is a relatively common genetic cardiac disease and the most frequent cause of sudden cardiac death (SCD) in young people including athletes. $^{1}{ }^{2}$ HCM is a

\section{KEY MESSAGES}

What is already known about the subject?

- Relation between $Q$ waves on electrocardiogram and late gadolinium enhancement on MRI reflecting myocardial fibrosis has been demonstrated by some studies.

What does this study add?

- Our study described a higher prevalence of $Q$ waves in patient with myocardial late gadolinium enhancement on MRI but without correlation concerning extent and location of late gadolinium enhancement (LGE) and $Q$ waves. We suggested that $Q$ waves are mainly explained by abnormal electrical activation due to asymmetrical hypertrophy.

How might this impact on clinical practice?

- LGE on MRI is associated with worse prognosis in hypertrophic cardiomyopathy (HCM). but absence of strong correlation with $Q$ waves should not allow us considering $Q$ waves as surrogate endpoint to predict LGE. MRI has to be performed to precise extent and location of LGE in HCM. Secondly, pathologic $Q$ waves on ECG could suggest an asymmetrical hypertrophy and could lead to further exploration in asymptomatic patient in order to screen HCM.

heterogeneous disease with a diverse anatomical and clinical presentation and course. $^{1}{ }^{3-5}$ Several risk markers for ventricular arrhythmia and SCD have been described and applied to manage the primary prevention of SCD in clinical practice with the use of implantable cardioverterdefibrillators therapy.

Cardiac MRI (CMR) may be considered as the gold-standard technique to assess left ventricular (LV) volume and mass ${ }^{4}{ }^{6}$ and consequently for the diagnosis of the different phenotypic patterns of HCM. ${ }^{35} 78$ CMR 
also contributes to the detection of myocardial fibrosis by late gadolinium enhancement (LGE) imaging. ${ }^{9} 10$ LGE has a high prevalence in HCM that may vary from $57 \%$ to $79 \%,{ }^{11} 12$ and its predictive role for cardiovascular death and SCD has been widely suggested. ${ }^{6} 10 \quad 13$ Recently, a meta-analysis including four studies and 1063 patients described extensive LGE as a significant predictive tool for adverse cardiovascular events in HCM. ${ }^{2} 56$

ECG is abnormal in $75-95 \%$ of patients with HCM and is useful for the screening of HCM. ${ }^{1}$ The patterns of ECG abnormalities are large and their mechanisms largely studied with poor correlation to morphology and severity of hypertrophy. ${ }^{14}{ }^{15}$ Pathologic $Q$ wave in HCM is one of the most studied ECG findings with different pathophysiology described. ${ }^{16}{ }^{17}$ In the era of CMR, some studies suggested an association between abnormal $Q$ wave and LGE. ${ }^{14} 18{ }^{19}$ However, few studies compared ECG findings to the mere presence of LGE.

The main aim of our study was to compare ECG characteristics including abnormal $\mathrm{Q}$ waves to the presence of LGE assessed by CMR and to identify ECG parameters that might be predictors of LGE.

\section{MATERIALS AND METHODS Study population}

Fifty consecutive patients with HCM referred to a university hospital for a CMR assessment between February 2008 and May 2012 were studied retrospectively. Diagnosis of LV hypertrophy (LVH) was made by twodimensional echocardiography and confirmed by CMR analysis. Morphological diagnosis of HCM was based on the association of unexplained LVH (maximal wall thickness $\geq 15 \mathrm{~mm}$ in sporadic adult patients or $\geq 13 \mathrm{~mm}$ in adult relatives of patients with confirmed HCM) with a non-dilated left ventricle in the absence of another cardiac or systemic disease capable of producing the

50 consecutive patients refered to CMR center for LV hypertrophy on clinical and echocardiographic settings

8 patients excluded from study:

- 2 for amyloidosis

2 for previous myocardial infarction

- 2 for severe hypertension

2 for left ventricular non-compaction criteria on CMR

42 patients with $\mathrm{HCM}$ in an analysis of CMR and ECG findings

Figure 1 Flow chart for retrospective analysis in order to compare CMR and ECG parameters in HCM. CMR, cardiac $\mathrm{MRI}$; HCM, hypertrophic cardiomyopathy; LV, left ventricular. magnitude of hypertrophy observed. ${ }^{1}{ }^{2}$ Forty-two patients comprised the final study group. Patients with LV non-compaction $(n=2),{ }^{20}$ severe hypertension $(n=2)$, previous myocardial infarction $(\mathrm{n}=2)$ and cardiac amyloidosis $(n=2)$ were excluded from the analysis (see figure 1). Clinical characteristics were collected through data extraction from medical records.

\section{ECG procedure and criteria}

A standard 12-lead ECG was obtained in all patients in the supine position during quiet respiration. Cardiac rhythm, PR interval (upper normal limit was $200 \mathrm{~ms}$ ), ${ }^{14}$ QRS duration, QRS axis and QT interval duration corrected for cardiac frequency (upper normal limits were $440 \mathrm{~ms}$ for men and $460 \mathrm{~ms}$ for women) ${ }^{14}$ were collected. Repolarisation abnormalities were defined as ST depression $\geq 0.1 \mathrm{mV}$ at $0.08 \mathrm{~s}$ from $\mathrm{J}$ point, asymmetrical $\mathrm{T}$ wave inversion $\geq 0.1 \mathrm{mV}$ deep in two or more leads except aVR, ST elevation $\geq 0.2 \mathrm{mV}^{15}{ }^{21}$ An abnormal $\mathrm{Q}$ wave was determined as described by Konno et $a l^{22}$ by a $\mathrm{Q}$ wave $>0.3 \mathrm{mV}$ in depth and/or $>0.04 \mathrm{~s}$ in duration in at least two leads except aVR. ${ }^{19} 22$

We assessed LVH with the Romhilt-Estes score ( $\geq 4$ for a probable LVH, $\geq 5$ for a definite LVH),${ }^{23}{ }^{24}$ the SokolowLyon voltage score (positive for a score $\geq 3.5 \mathrm{mV}$ ), ${ }^{23}{ }^{25}$ the Sokolow-Lyon product (positive for a score $\geq 371 \mathrm{mV}$ / $\mathrm{ms}),{ }^{26}$ the Cornell voltage score $(\geq 2.8 \mathrm{mV}$ for men and $\geq 2 \mathrm{mV}$ for women $)^{27} 28$ and the Cornell product $(\geq 244 \mathrm{mV} / \mathrm{ms})$.

\section{CMR protocol}

CMR was performed with a 1.5-T imager (Avanto, Siemens, Erlangen, Germany) by using an eight-element phased-array cardiac receiver coil. Localisation was performed using breath-hold real-time and steady-state free precession images of true anatomical axes of the heart.

Functional parameters were determined with cine imaging using a segmented steady-state free precession pulse sequence in multiple short-axis and four-chamber views covering the entire left ventricle. Typical in-plane resolution was $1.6 \times 1.9 \mathrm{~mm}$, with a section thickness of $7.0 \mathrm{~mm}$ (repetition time/echo time: $2.6 \mathrm{~ms} / 1.3 \mathrm{~ms}$; flip angle: $80^{\circ}$; matrix: 256×208; temporal resolution: 35-45 ms).

LGE was performed 12-15 min after gadolinium-based contrast agent administration (cumulative dose, $0.2 \mathrm{mmol} / \mathrm{kg}$ of body weight) with a two-dimensional segmented inversion recovery gradient-echo pulse sequence. Typical in-plane resolution was $1.68 \times 1.68 \mathrm{~mm}$; section thickness was $7.0 \mathrm{~mm}$ (TE: $4.66 \mathrm{~ms}$; flip angle: $30^{\circ}$; imaging was triggered to every other heartbeat; matrix: 256×208). The inversion time was individually adjusted to null normal myocardium.

\section{Image analysis}

All images were analysed at the central core laboratory by two investigators blinded to all patient data and ECG findings. Commercial software (Qmass MR 6.2.1; Leiden, The Netherlands) was used for the analysis. 
Endocardial and epicardial borders were outlined manually on all end-diastolic and end-systolic short-axis cine slices. LV end-systolic and end-diastolic volumes, LV ejection fraction (EF) and LV mass were then calculated in a standard fashion. The LV maximal wall thickness was automatically measured by the software.

Short-axis slices were divided into four equal parts: septal, anterior, lateral and inferior. The ratio of septal to posterior wall thickness was calculated. ${ }^{19}$

As described previously, ${ }^{3}$ the pattern of HCM was defined according to the number of hypertrophied segments in focal HCM (1-2 hypertrophic segments), moderate HCM (3-7 segments) and diffuse HCM ( $\geq 8$ segments). Then a second classification ${ }^{4}$ was determined according to the $\mathrm{LV}$ mass index (LVMI): normal LVMI (men $<81 \mathrm{~g} / \mathrm{m}^{2}$, women $<62 \mathrm{~g} / \mathrm{m}^{2}$ ), mildly increased LVMI (men $81-91 \mathrm{~g} / \mathrm{m}^{2}$, women $62-69 \mathrm{~g} / \mathrm{m}^{2}$ ), markedly increased LVMI (men $>91 \mathrm{~g} / \mathrm{m}^{2}$, women $>69 \mathrm{~g} / \mathrm{m}^{2}$ ). Four-chamber views were used to assess the presence of apical hypertrophy.

LGE was considered to be present (LGE (+) vs LGE (-) groups) when the signal of any area of the myocardium was highly hyperintense in artefact-free images. Semiautomatic quantification of the LGE mass was made using the 'full width half maximum' (FWHM) method. ${ }^{29}$ The extent of LGE was quantified as a percentage of the LV mass. ${ }^{1029} 30$

\section{Statistical analysis}

Continuous variables were presented as mean \pm SD. Categorical variables were given as a number and percentage. Between-group differences were assessed using the Pearson $\chi^{2}$ test or Fisher's exact test (for subgroups containing $\leq 5$ observations) for categorical data and $t$ test for continuous data. Statistical significance was defined as $\mathrm{p}<0.05$ for all tests. Statistical analysis was performed by using SPSS V.15 (SPSS, Inc, Chicago, Illinois, USA).

\section{RESULTS}

\section{Clinical characteristics}

Forty-two patients were $47 \pm 16$ years of age, of which 28.5\% ( $\mathrm{n}=12$ ) were female (table 1). Family history of HCM and sudden death were, respectively, $31 \% \quad(n=13)$ and $15 \%(\mathrm{n}=6)$, without any difference between the two groups. Seventy-four per cent $(n=31)$ of patients received medical therapy most often by $\beta$-blockers $(71.8 \% ; \mathrm{n}=30)$ and only one took a calcium antagonist.

\section{ECG characteristics}

Sinus rhythm was encountered in $93 \%$ of patients (table 2). Repolarisation was normal in $14 \%$ of cases $(n=6)$; the most frequent repolarisation abnormalities were ST segment depression in 24 patients $(55 \%)$ and negative $\mathrm{T}$ wave in 32 patients $(76 \%)$. There was no left bundle branch block.

\section{CMR findings}

The mean end-diastolic maximal wall thickness was $19.16 \pm 3.8 \mathrm{~mm}$, ranging from 13.2 to $27.3 \mathrm{~mm}$ (table 3 ). LGE was found in 25 patients $(59.5 \%)$. History of

\begin{tabular}{|c|c|c|c|c|}
\hline & All patients $(n=42)$ & LGE (-) $(n=17 ; 40.5 \%)$ & LGE (+) (n=25; 59.5\%) & p Value \\
\hline Age at CMR & $47.57 \pm 16$ & $50.29 \pm 16.58$ & $45.73 \pm 15.68$ & NS \\
\hline Female & $12(28.5)$ & $5(29.4)$ & $7(28)$ & NS \\
\hline Hypertension & $15(35.7)$ & 9 (52.9) & $6(24)$ & 0.055 \\
\hline Family history of $\mathrm{HCM}$ & $13(30.9)$ & $4(23.5)$ & $9(36)$ & NS \\
\hline Family history of sudden death & $6(15)$ & $2(11.7)$ & $4(16)$ & NS \\
\hline Atrial fibrillation history & $10(23.8)$ & $4(23.5)$ & $6(24)$ & NS \\
\hline Chest pain & $11(26.2)$ & $8(47)$ & $3(12)$ & 0.029 \\
\hline Syncope & $6(14.3)$ & $1(5.8)$ & $5(20)$ & NS \\
\hline Heart failure & $7(16.7)$ & $2(11.7)$ & $5(20)$ & NS \\
\hline NYHA class & & & & NS \\
\hline 1 & $30(71.4)$ & $12(70.5)$ & $18(72)$ & \\
\hline 2 & $10(23.8)$ & $4(23.5)$ & $6(24)$ & \\
\hline 3 & $2(4.8)$ & $1(5.8)$ & $1(4)$ & \\
\hline Mean NYHA class & $1.33 \pm 0.57$ & $1.35 \pm 0.58$ & $1.32 \pm 0.55$ & NS \\
\hline$\beta$-blockers & $30(71.4)$ & $12(70.5)$ & $18(72)$ & NS \\
\hline Calcium antagonist & $1(2.4)$ & $0(0)$ & $1(4)$ & NS \\
\hline Echocardiography & & & & NS \\
\hline Ejection fraction & $65 \pm 9$ & $63 \pm 9$ & $66 \pm 9$ & NS \\
\hline Maximum wall thickness $(\mathrm{mm})$ & $18 \pm 3$ & $17 \pm 3$ & $18 \pm 4$ & NS \\
\hline Wall thickness >30 mm & $1(2.4)$ & $0(0)$ & $1(4)$ & NS \\
\hline Rest LVOTO >30 mm Hg & $1(2.4)$ & $1(5.8)$ & $0(0)$ & NS \\
\hline Non-sustained VT on $24 \mathrm{H}$-Holter ECG & $9(21.4)$ & $3(17.6)$ & $6(24)$ & NS \\
\hline Abnormal BP response to exercise & $4(9.5)$ & $1(5.8)$ & $3(2)$ & NS \\
\hline
\end{tabular}


Table 2 ECG characteristics

Sinus rhythm

Atrial fibrillation

QRS duration

Normal repolarisation

ST elevation

ST depression

Negative $T$ wave

Abnormal $Q$ wave

Abnormal $Q$ wave in $\mathrm{V} 1-\mathrm{V} 2$

Abnormal $Q$ wave in $\mathrm{D} 1-\mathrm{aVL}$

Abnormal $Q$ wave in V3-V4

Abnormal $Q$ wave in V5-V6

Abnormal $Q$ wave in DII-DIII-aVF

Sokolow $\geq 3.5 \mathrm{mV}$

Cornell $\geq 2 \mathrm{mV}$ for women, $\geq 2.8 \mathrm{mV}$ for men

Romhilt-Estes score

Sokolow product $(\mathrm{mV} / \mathrm{ms})$

Cornell product $(\mathrm{mV} / \mathrm{ms})$

\begin{tabular}{|c|c|c|c|}
\hline All patients $(n=42)$ & $\begin{array}{l}\text { LGE }(-) \\
(n=17 ; 40.5 \%)\end{array}$ & $\begin{array}{l}\text { LGE (+) } \\
(n=25 ; 59.5 \%)\end{array}$ & p Value \\
\hline 39 (93) & $16(94)$ & $23(92)$ & NS \\
\hline $3(7)$ & $1(6)$ & $2(8)$ & NS \\
\hline $102.14 \pm 18.4$ & $101.06 \pm 19.6$ & $102.88 \pm 17.9$ & NS \\
\hline $6(14)$ & $4(23)$ & $2(8)$ & NS \\
\hline $11(26)$ & $6(35)$ & $5(20)$ & NS \\
\hline $23(23)$ & $10(59)$ & $13(52)$ & NS \\
\hline $32(76)$ & $12(71)$ & $20(80)$ & NS \\
\hline $17(40)$ & $2(12)$ & $15(60)$ & 0.003 \\
\hline $0(0)$ & $0(0)$ & $0(0)$ & NA \\
\hline $9(21)$ & $0(0)$ & $9(36)$ & 0.006 \\
\hline $3(7)$ & $0(0)$ & $3(12)$ & NS \\
\hline $5(12)$ & $0(0)$ & $5(20)$ & 0.07 \\
\hline $6(14)$ & $2(0)$ & $4(16)$ & NS \\
\hline $12(29)$ & $6(35)$ & $6(24)$ & NS \\
\hline $14(33)$ & $10(59)$ & $4(16)$ & 0.007 \\
\hline $4.5 \pm 3$ & $5 \pm 3.45$ & $4 \pm 2.66$ & NS \\
\hline $243.1 \pm 115.3$ & $258.1 \pm 112.3$ & $233.5 \pm 118.5$ & NS \\
\hline $233.3 \pm 103.1$ & $251.0 \pm 109.9$ & $221.4 \pm 98.2$ & NS \\
\hline
\end{tabular}

Data are presented as the mean value \pm SD or number (\%) of subjects.

LGE, late gadolinium enhancement; NA, not available; NS, not significant. hypertension was present in $35 \%$ of patients with a trend towards higher rates in patients without LGE (52.9\% vs $24 \%$; $\mathrm{p}=0.056$; table 1 ). Notably, patients with LGE (-) patients presented a higher prevalence of chest pain $(47 \% ; n=8)$ compared to the LGE (+) group $(12 \% ; \mathrm{n}=3 ; \mathrm{p}=0.015$; table 1$)$.

The mean left ventricular mass (LVM) was $141.2 \pm 52 \mathrm{~g}$ in all population without difference between two groups. Similarly, there was no difference concerning LVEF and LV volumes. The ratio of septal to posterior wall thickness was significantly higher in patients with LGE than in those without. No difference was found between LGE (+) and LGE (-) in the HCM pattern and mass distribution. None of the patients had apical hypertrophy on four-chamber views.

The mean wall thickness of LGE (+) segments was $18.2 \pm 3.0 \mathrm{~mm}$ and each and every LGE (+) segment showed hypertrophy. The LGE extent ranged from 1.3 to $35 \mathrm{~g}$ (mean $12 \pm 10 \mathrm{~g}$ ), corresponding to $1-29 \%$ (mean $9 \pm 8 \%$ ) of the entire myocardium.

\section{Table 3 CMR findings}

\begin{tabular}{|c|c|c|c|c|}
\hline & All patients $(n=42)$ & LGE (-) (n=17; 40.5\%) & LGE (+) (n=25; 59.5\%) & p Value \\
\hline LVEF (\%) & $62 \pm 9$ & $64 \pm 12$ & $61 \pm 7$ & NS \\
\hline LVEDV index $\left(\mathrm{mL} / \mathrm{m}^{2}\right)$ & $80 \pm 18$ & $85 \pm 17$ & $77 \pm 18$ & NS \\
\hline LVESV index $\left(\mathrm{mL} / \mathrm{m}^{2}\right)$ & $31 \pm 12$ & $33 \pm 17$ & $30 \pm 8$ & NS \\
\hline LVM (g) & $141 \pm 52$ & $143 \pm 60$ & $140 \pm 46$ & NS \\
\hline LVMI $\left(\mathrm{g} / \mathrm{m}^{2}\right)$ & $73 \pm 25$ & $75 \pm 30$ & $72 \pm 22$ & NS \\
\hline Maximum wall thickness (mm) & $19 \pm 4$ & $18 \pm 3$ & $20 \pm 4$ & 0.074 \\
\hline LGE mass $(\mathrm{g})$ & $12 \pm 10$ & $0 \pm 0$ & $12 \pm 10$ & NA \\
\hline LGE mass/LVM (\%) & $9 \pm 8$ & $0 \pm 0$ & $9 \pm 8$ & NA \\
\hline Septal WT/posterior WT ratio & $1.8 \pm 0.6$ & $1.5 \pm 0.4$ & $2.0 \pm 0.7$ & 0.01 \\
\hline HCM pattern & & & & NS \\
\hline Focal HCM & $12(28.6)$ & $6(35)$ & $6(24)$ & \\
\hline Moderate HCM & $19(45.2)$ & $7(41.1)$ & $12(48)$ & \\
\hline Diffuse HCM & $11(26.2)$ & $4(23.5)$ & $7(28)$ & \\
\hline LVMI class & & & & NS \\
\hline Normal & $29(69)$ & $11(64.7)$ & $18(72)$ & \\
\hline Mildly increased & $2(4.7)$ & $2(11.7)^{\prime}$ & $0(0)$ & \\
\hline Markedly increased & $11(26.2)$ & $4(23.5)$ & $7(28)$ & \\
\hline
\end{tabular}


Figure 2 Illustration of discordance between location of $Q$ waves on ECG derivations and location of LGE in the myocardium on CMR.

(A) Incidence of LGE within cited location among all patients $(n=42)$. LGE was predominantly on the anterior, septal and inferior territory. (B) Incidence of $Q$ waves in the cited derivations among all patients. $Q$ waves were more likely in the derivations corresponding to the lateral territory. (C) Comparison of septal to posterior WT ratio according to the presence $(Q+)$ or absence $(Q$ - ) of Abnormal $Q$ waves in their different derivations. * $p<0.05$. CMR, cardiac MRI; HCM, hypertrophic cardiomyopathy; LGE, late gadolinium enhancement; WT, wall thickness.
A
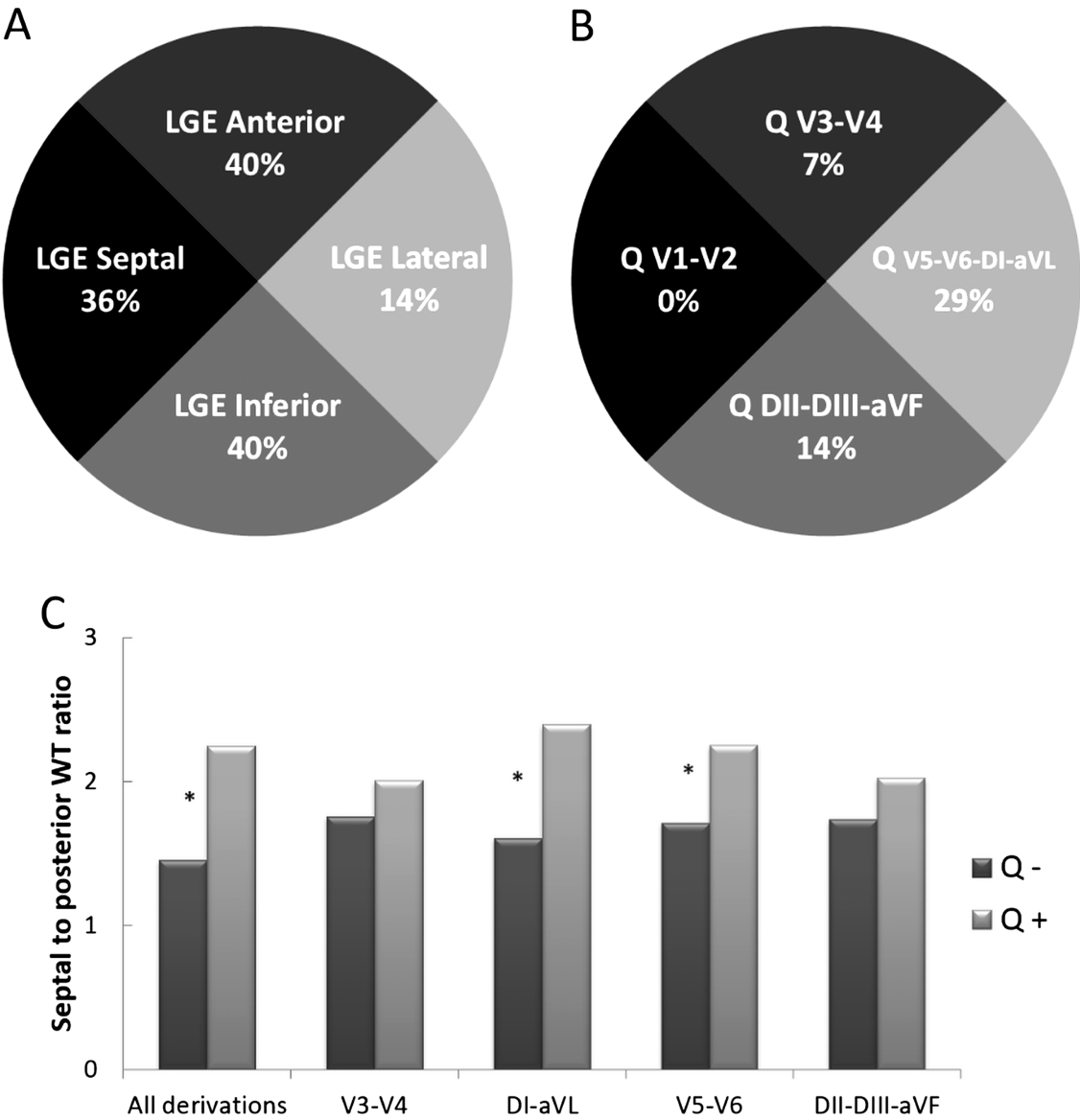

\section{Relationships between ECG and LGE}

ECG parameters including conduction disturbances, QRS axis, repolarisation abnormalities and LV hypertrophy scores did not show any difference in patients with or without LGE (table 2).

Patients with LGE showed a greater prevalence of abnormal $Q$ waves $(60 \% ; n=15$ vs $12 \%$; $n=2)$ than those without ( $\mathrm{p}=0.002$; table 2$)$.

However, on segmental analysis, there was no relation between $Q$ waves' location on ECG and LGE territory (see figure 2). Remarkably, the preferential location of $Q$ waves was DI-aVL, whereas only one patient presented with LGE on the lateral wall (figure 2).

\section{Q waves and quantitative analysis of LGE}

Among patients with LGE ( $\mathrm{n}=25$; table 4$)$, the LGE extent was similar in patients with or without abnormal Q waves.

Table 4 Abnormal $Q$ waves and quantitative analysis of $L G E$

\begin{tabular}{lccc}
\hline & No abnormal Q wave $(\mathbf{n = 1 0} \mathbf{4 0 \%})$ & Abnormal Q wave $(\mathbf{n = 1 5} ; \mathbf{6 0 \% )}$ & $\mathbf{p ~ V a l u e ~}$ \\
\hline LVEF $(\%)$ & $62 \pm 8$ & $60 \pm 7$ & $\mathrm{NS}$ \\
LVEDV index $\left(\mathrm{mL} / \mathrm{m}^{2}\right)$ & $79 \pm 11$ & $76 \pm 22$ & $\mathrm{NS}$ \\
LVESV index $\left(\mathrm{mL} / \mathrm{m}^{2}\right)$ & $30 \pm 6$ & $30 \pm 9$ & $\mathrm{NS}$ \\
LVM $(\mathrm{g})$ & $154 \pm 56$ & $130 \pm 38$ & $\mathrm{NS}$ \\
LVMI $\left(\mathrm{g} / \mathrm{m}^{2}\right)$ & $78 \pm 24$ & $69 \pm 20$ & $\mathrm{NS}$ \\
Maximum wall & $20 \pm 5$ & $20 \pm 4$ & $\mathrm{NS}$ \\
thickness $(\mathrm{mm})$ & $12 \pm 10$ & $12 \pm 10$ & $\mathrm{NS}$ \\
LGE mass $(\mathrm{g})$ & $7 \pm 7$ & $10 \pm 8$ & 0.012 \\
LGE mass/LVM $(\%)$ & $1.6 \pm 0.5$ & $2.2 \pm 0.7$ & \\
Septal WT/posterior & &
\end{tabular}

Data are presented as the mean value \pm SD.

HCM, hypertrophic cardiomyopathy; LVEDV, LV end-diastolic volume; LGE, late gadolinium enhancement; LVEF, left ventricular ejection fraction; LVESV, LV end-systolic volume; LVM, Left ventricle mass; LVMI, left ventricular mass index; NS, not significant; WT, wall thickness. 


\section{Relationship between septal to posterior wall thickness ratio and abnormal $Q$ waves}

Patients with abnormal $Q$ waves had a significantly higher septal to posterior wall thickness ratio $(2.2 \pm 0.7)$ compared to those without abnormal $Q$ waves $(1.6 \pm 0.5 ; \mathrm{p}<0.001$; table 4 and figure 2). This difference was also encountered among the subgroup of patients with LGE. Patients with DI-aVL $Q$ waves also had a higher ratio than those without (2.4 \pm 0.7 vs $1.6 \pm 0.5 ; p=0.001$; figures 2 and 3 ).

\section{DISCUSSION}

In the present study, we exhibited that patients with LGE on CMR more often had $Q$ waves on ECG but that the location of LGE in the myocardium was not correlated to the corresponding derivation on ECG. The presence of abnormal $Q$ waves seems to be better related to higher septal to posterior wall thickness than LGE.

LGE was found in $59.5 \%$ of the 42 patients. Recent studies considering LGE in HCM showed similar data from $55 \%$ to $63 \% .^{10} 31$ As previously described, we found a higher prevalence of abnormal $Q$ waves in patients with LGE (+). ${ }^{9} 10 \quad 31$ We found that $60 \%$ of patients with LGE presented with $\mathrm{Q}$ waves on the ECG, but the location of $\mathrm{Q}$ waves on the ECG was dissimilar to those of LGE on CMR in our study. For example, only one patient with the DI-VL $Q$ wave exhibited lateral LGE. The same result was suggested in the study by Dumont $e t a l^{18}$ concerning the predominant location of septal LGE in patients with lateral $\mathrm{Q}$ waves. In contrast, Papavassiliu et $a l^{19}$ described a good correspondence between $Q$ waves and LGE though defining only three main territories (anterior, inferior and lateral)
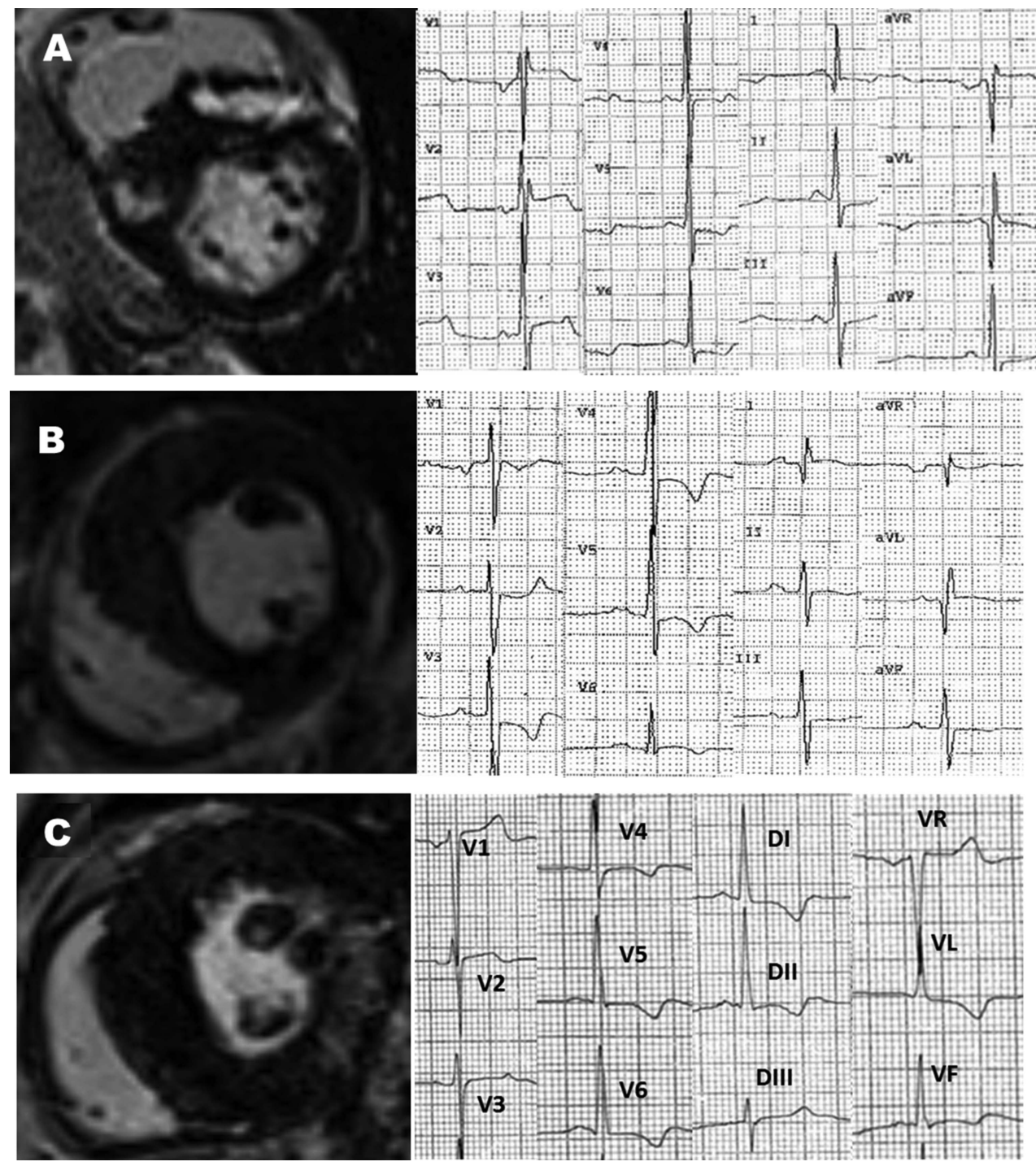

Figure 3 Examples of association between CMR features and abnormal Q waves. (A) HCM with high septal to posterior WT ratio, LGE on right to left ventricular junctions, $Q$ waves in DI-VL discordance between location of $Q$ waves and $L G E$. (B) $Q$ waves in inferior leads associated with asymmetrical HCM but no LGE. (C) Diffuse HCM with lower septal to posterior WT ratio, LGE in lateral wall but no Q waves. CMR, cardiac MRI; HCM, hypertrophic cardiomyopathy; LGE, late gadolinium enhancement; WT, wall thickness. 
corresponding to the coronary arteries ${ }^{32}$-as a consequence, the interventricular septum was not individualised, although it is a common location of hypertrophy and LGE. ${ }^{18}{ }^{33}$ Moreover, owing to the high incidence of LGE in the superior and inferior right ventricular insertion points, the American Heart Association 17-segment model was not used for LGE analysis. ${ }^{18} 3234$

Among patients with LGE, those with abnormal $Q$ waves did not present a higher extent of LGE as assessed by a semiautomatic quantitative analysis technique. This result is also different from the study by Papavassiliu et al, because the quantitative analysis was performed by the visual assessment of the transmural nature of LGE and not the absolute LGE extent. To the best of our knowledge, there is no other study on pathologic $Q$ waves and quantitative LGE evaluation. FWHM is a semiautomatic technique to assess LGE mass. Studies demonstrated that FWHM was well correlated with ex-vivo quantification of fibrosis and adverse outcome. ${ }^{10}{ }^{30} \mathrm{In}$ study by Spiewak et $a l^{29}$ there was no difference in mass of LGE assessment with FWHM technique and 6-SD (6standard deviations) threshold technique when compared to visual planimetry. In this study, FWHM technique had the best reproducibility.

The pathophysiology of abnormal $Q$ waves in HCM is debated and two main hypotheses have been described. ${ }^{35} \mathrm{Q}$ waves in HCM were first correlated with presence of myocardial fibrosis in old necropsy studies. ${ }^{36}$ Later, Maron $e t a l^{77}$ explained $\mathrm{Q}$ waves by the loss of local electrical forces secondary to transmural scar. This was again supported in a previous CMR study, but a key role was also given to the distribution of hypertrophy and particularly to the increase of the septal to posterior wall thickness ratio. ${ }^{19}$ Indeed, abnormal electrical activation of the markedly hypertrophied septum compared to normal posterior wall thickness is another explanation to abnormal $\mathrm{Q}$ waves considering several echocardiographic, ${ }^{17} \quad{ }^{38}$ ECG $^{39}$ and electrophysiological studies. ${ }^{16}$ Consistent with this hypothesis, two studies exhibited a disappearance of abnormal $Q$ waves after septal myectomy. ${ }^{40}{ }^{41}$ In our study, not only was the septal to posterior wall thickness ratio most common in patients with $Q$ waves but also it presented with higher values, even among patients with LGE. This difference was present in segmental analysis considering DI-aVL Q waves, the most frequent $Q$ wave location in our study. Thus, the hypertrophy pattern seems to be predominant in the pathophysiology of $Q$ waves considering the lack of correlation of $Q$ waves with the LGE location and its quantitative analysis. ${ }^{19}$

The results of this study should be interpreted in the light of certain limitations. First, the retrospective nature of the study may have introduced selection biases. The number of patients is limited and in one single centre compared to some prospective or retrospective studies on HCM, ${ }^{3} 33$ and hypertrophy was mildly severe considering a great number of focal and intermediate patterns as described by Maron et al and few massive septal hypertrophy ( $\geq 30 \mathrm{~mm}$ ) and few LV outflow tract obstructions $\geq 30 \mathrm{~mm} \mathrm{Hg}$. This limit could have biased the characteristics of these patients with HCM.

In addition, diffuse fibrosis was exclusively analysed by LGE and CMR studies including T1 mapping sequences might be of interest to investigate HCM.

Finally, genetic testing was not available for our patients. However, some ECG differences and prognosis impact has been described in line with genetics. ${ }^{42}{ }^{43}$ Moreover, the monocentric nature of our work may be responsible for the selection of some specific genetic mutations predominantly encountered in our region.

\section{CONCLUSION}

In HCM, it seems that the presence and extent of LGE cannot be presumed by any ECG parameter. Abnormal $\mathrm{Q}$ waves on the ECG may be partly attributable to the septal to posterior wall thickness ratio rather than myocardial fibrosis.

Contributors SG, GC and VM performed CMR analysis. SG and LB contributed to data management. $L B, F P, A F$ and $S W$ were involved in reviewing.

Funding This research received no specific grant from any funding agency in the public, commercial or not-for-profit sectors.

Competing interests None.

Ethics approval Comité d'éthique CHU Angers.

Provenance and peer review Not commissioned; externally peer reviewed.

Data sharing statement No additional data are available.

Open Access This is an Open Access article distributed in accordance with the Creative Commons Attribution Non Commercial (CC BY-NC 3.0) license, which permits others to distribute, remix, adapt, build upon this work noncommercially, and license their derivative works on different terms, provided the original work is properly cited and the use is non-commercial. See: http:// creativecommons.org/licenses/by-nc/3.0/

\section{REFERENCES}

1. Maron BJ. Hypertrophic cardiomyopathy: a systematic review. JAMA 2002;287:1308-20.

2. Gersh BJ, Maron BJ, Bonow RO, et al. 2011 ACCF/AHA guideline for the diagnosis and treatment of hypertrophic cardiomyopathy: a report of the American College of Cardiology Foundation/American Heart Association Task Force on Practice Guidelines. Circulation 2011;124:e783-831.

3. Maron MS, Maron BJ, Harrigan C, et al. Hypertrophic cardiomyopathy phenotype revisited after 50 years with cardiovascular magnetic resonance. J Am Coll Cardiol 2009;54:220-8.

4. Olivotto I, Maron MS, Autore C, et al. Assessment and significance of left ventricular mass by cardiovascular magnetic resonance in hypertrophic cardiomyopathy. J Am Coll Cardiol 2008;52:559-66.

5. HAS HAdS. Protocole National de Soins "Cardiopathie Hypertrophique". 2011.

6. Green JJ, Berger JS, Kramer CM, et al. Prognostic value of late gadolinium enhancement in clinical outcomes for hypertrophic cardiomyopathy. JACC Cardiovasc Imaging 2012;5:370-7.

7. Moon JC, Fisher NG, McKenna WJ, et al. Detection of apical hypertrophic cardiomyopathy by cardiovascular magnetic resonance in patients with non-diagnostic echocardiography. Heart 2004;90:645-9.

8. Rickers C, Wilke NM, Jerosch-Herold M, et al. Utility of cardiac magnetic resonance imaging in the diagnosis of hypertrophic cardiomyopathy. Circulation 2005;112:855-61.

9. Moon JC, Reed E, Sheppard MN, et al. The histologic basis of late gadolinium enhancement cardiovascular magnetic resonance in hypertrophic cardiomyopathy. J Am Coll Cardiol 2004;43:2260-4. 
10. O'Hanlon R, Grasso A, Roughton M, et al. Prognostic significance of myocardial fibrosis in hypertrophic cardiomyopathy. J Am Coll Cardiol 2011:56:867-74.

11. Kwon DH, Smedira NG, Rodriguez ER, et al. Cardiac magnetic resonance detection of myocardial scarring in hypertrophic cardiomyopathy: correlation with histopathology and prevalence of ventricular tachycardia. J Am Coll Cardiol 2009;54:242-9.

12. Moon JC, McKenna WJ, McCrohon JA, et al. Toward clinical risk assessment in hypertrophic cardiomyopathy with gadolinium cardiovascular magnetic resonance. J Am Coll Cardiol 2003:41:1561-7.

13. Adabag AS, Maron BJ, Appelbaum E, et al. Occurrence and frequency of arrhythmias in hypertrophic cardiomyopathy in relation to delayed enhancement on cardiovascular magnetic resonance. J Am Coll Cardiol 2008;51:1369-74.

14. Delcre SD, Di Donna P, Leuzzi S, et al. Relationship of ECG findings to phenotypic expression in patients with hypertrophic cardiomyopathy: a cardiac magnetic resonance study. Int J Cardiol 2013:167:1038-45.

15. Savage DD, Seides SF, Clark CE, et al. Electrocardiographic findings in patients with obstructive and nonobstructive hypertrophic cardiomyopathy. Circulation 1978;58:402-8.

16. Cosio $\mathrm{FG}$, Moro $\mathrm{C}$, Alonso $\mathrm{M}$, et al. The $\mathrm{Q}$ waves hypertrophic cardiomyopathy: an electrophysiologic study. N Engl J Med 1980;302:96-9.

17. Lemery R, Kleinebenne A, Nihoyannopoulos $\mathrm{P}$, et al. Q waves in hypertrophic cardiomyopathy in relation to the distribution and severity of right and left ventricular hypertrophy. J Am Coll Cardiol 1990;16:368-74.

18. Dumont $\mathrm{CA}$, Monserrat $\mathrm{L}$, Soler $\mathrm{R}$, et al. Interpretation of electrocardiographic abnormalities in hypertrophic cardiomyopathy with cardiac magnetic resonance. Eur Heart $J$ 2006;27:1725-31.

19. Papavassiliu T, Fluchter S, Haghi D, et al. Extent of myocardial hyperenhancement on late gadolinium-enhanced cardiovascular magnetic resonance correlates with q waves in hypertrophic cardiomyopathy. J Cardiovasc Magn Reson 2007;9:595-603.

20. Petersen SE, Selvanayagam JB, Wiesmann F, et al. Left ventricular non-compaction: insights from cardiovascular magnetic resonance imaging. J Am Coll Cardiol 2005;46:101-5.

21. Hancock EW, Deal BJ, Mirvis DM, et al. AHA/ACCF/HRS recommendations for the standardization and interpretation of the electrocardiogram: part V: electrocardiogram changes associated with cardiac chamber hypertrophy: a scientific statement from the American Heart Association Electrocardiography and Arrhythmias Committee, Council on Clinical Cardiology; the American College of Cardiology Foundation; and the Heart Rhythm Society. Endorsed by the International Society for Computerized Electrocardiology. J Am Coll Cardiol 2009;53:992-1002.

22. Konno T, Shimizu M, Ino $\mathrm{H}$, et al. Diagnostic value of abnormal $\mathrm{Q}$ waves for identification of preclinical carriers of hypertrophic cardiomyopathy based on a molecular genetic diagnosis. Eur Heart J 2004;25:246-51.

23. Buchner S, Debl K, Haimerl J, et al. Electrocardiographic diagnosis of left ventricular hypertrophy in aortic valve disease: evaluation of ECG criteria by cardiovascular magnetic resonance. J Cardiovasc Magn Reson 2009;11:18.

24. Romhilt DW, Estes EH Jr. A point-score system for the ECG diagnosis of left ventricular hypertrophy. Am Heart J 1968;75:752-8.

25. Sokolow M, Lyon TP. The ventricular complex in left ventricular hypertrophy as obtained by unipolar precordial and limb leads. Am Heart J 1949;37:161-86.
26. Molloy TJ, Okin PM, Devereux RB, et al. Electrocardiographic detection of left ventricular hypertrophy by the simple QRS voltage-duration product. J Am Coll Cardiol 1992;20:1180-6.

27. Casale PN, Devereux RB, Kligfield P, et al. Electrocardiographic detection of left ventricular hypertrophy: development and prospective validation of improved criteria. J Am Coll Cardiol 1985;6:572-80.

28. Okin PM, Devereux RB, Jern S, et al. Relation of echocardiographic left ventricular mass and hypertrophy to persistent electrocardiographic left ventricular hypertrophy in hypertensive patients: the LIFE Study. Am J Hypertens 2001;14:775-82.

29. Spiewak M, Malek LA, Misko J, et al. Comparison of different quantification methods of late gadolinium enhancement in patients with hypertrophic cardiomyopathy. Eur J Radiol 2010;74:e149-53.

30. Amado LC, Gerber BL, Gupta SN, et al. Accurate and objective infarct sizing by contrast-enhanced magnetic resonance imaging in a canine myocardial infarction model. J Am Coll Cardiol 2004:44:2383-9.

31. Maron MS, Appelbaum E, Harrigan CJ, et al. Clinical profile and significance of delayed enhancement in hypertrophic cardiomyopathy. Circ Heart Fail 2008;1:184-91.

32. Cerqueira MD, Weissman NJ, Dilsizian V, et al. Standardized myocardial segmentation and nomenclature for tomographic imaging of the heart: a statement for healthcare professionals from the Cardiac Imaging Committee of the Council on Clinical Cardiology of the American Heart Association. Circulation 2002;105:539-42.

33. Rubinshtein R, Glockner JF, Ommen SR, et al. Characteristics and clinical significance of late gadolinium enhancement by contrast-enhanced magnetic resonance imaging in patients with hypertrophic cardiomyopathy. Circ Heart Fail 2010;3:51-8.

34. Rudolph A, Abdel-Aty H, Bohl S, et al. Noninvasive detection of fibrosis applying contrast-enhanced cardiac magnetic resonance in different forms of left ventricular hypertrophy relation to remodeling. J Am Coll Cardiol 2009;53:284-91.

35. Maron BJ. Q waves in hypertrophic cardiomyopathy: a reassessment. J Am Coll Cardiol 1990;16:375-6.

36. Bahl OP, Walsh TJ, Massie E. Electrocardiography and vectorcardiography in idiopathic hypertrophic subaortic stenosis. $A m$ J Med Sci 1970;259:262-71.

37. Maron BJ, Epstein SE, Roberts WC. Hypertrophic cardiomyopathy and transmural myocardial infarction without significant atherosclerosis of the extramural coronary arteries. Am J Cardiol 1979;43:1086-102.

38. Maron BJ, Wolfson JK, Ciro E, et al. Relation of electrocardiographic abnormalities and patterns of left ventricular hypertrophy identified by 2-dimensional echocardiography in patients with hypertrophic cardiomyopathy. Am J Cardiol 1983;51:189-94.

39. Mori H, Ogawa S, Noma S, et al. Pattern of myocardial hypertrophy as a possible determinant of abnormal $Q$ waves in hypertrophic cardiomyopathy. Jpn Circ J 1983;47:513-21.

40. Wigle ED, Baron RH. The electrocardiogram in muscular subaortic stenosis. Effect of a left septal incision and right bundle-branch block. Circulation 1966;34:585-94.

41. Braudo M, Wigle ED, Keith JD. A distinctive electrocardiogram in muscular subaortic stenosis due to ventricular septal hypertrophy. Am J Cardiol 1964;14:599-607.

42. Bos JM, Towbin JA, Ackerman MJ. Diagnostic, prognostic, and therapeutic implications of genetic testing for hypertrophic cardiomyopathy. J Am Coll Cardiol 2009;54:201-11.

43. Jouven X, Hagege A, Charron P, et al. Relation between QT duration and maximal wall thickness in familial hypertrophic cardiomyopathy. Heart 2002;88:153-7. 